Commercial expansion in São

Paulo: 'decay' and 'idleness' in the discourses of contemporary men, travelers and public authorities, 1782-1822.

\title{
Expansão mercantil em São Paulo: 'decadência' e 'vadiagem' nos discursos de memorialistas, viajantes e autoridades públicas, 1782-1822
}

\section{Ana Paula Medicci}

Mestranda do programa de pósgraduação do departamento de História da FFLCH/USP, sob orientação da Profa. Dra. Cecilia Helena de Salles Oliveira.

\begin{abstract}
Resumo
A presente pesquisa discute a expansão da lavoura mercantil em São Paulo entre 1782 e 1822, com base na análise da legislação, de memórias de contemporâneos e da documentação e de relatórios, elaborados pelos governadores da Capitania. Para memorialistas e capitães generais, o aumento da produção comercializável dependia da implantação de novas práticas agrícolas que levassem os homens livres, especialmente os índios, a se ocuparem em rotinas de trabalho consideradas produtivas, diminuindo ao máximo 0 tempo "ocioso" dessa população. Daí, os principais temas do discurso memorialista e governamental serem a "decadência" de São Paulo e a necessidade de "restabelecer" sua povoação e agricultura, por meio da incorporação e do controle da mão-de-obra disponível.
\end{abstract}

\begin{abstract}
This research discusses the expansion of commercial agriculture in São Paulo between 1782 and 1822, based on the analysis of legislation, the memories written by contemporary people and both documents and reports elaborated by the governors of the 'captaincy'. In memoirs and governmental documents, the increase of production bound to commercialization depended on the implementation of new agricultural practices that made free men, specially native people, occupy themselves in labor routines considered productive, decreasing as much as possible the 'inactive' time of this population. Therefore, the most important topics of the memoirs and governmental discourses are the 'decay' of São Paulo and the urgency of 'restoring' its settlement and agriculture, through the incorporation and control of the available labour force.
\end{abstract}

\section{Palavras-chave}

São Paulo, vocabulário político, viajantes, agricultura, comércio, legislação. Keywords

São Paulo, political vocabulary, travelers, agriculture, trade, legislation. 
Em 1766, o Morgado de Mateus escreveu ao Conde de Oeiras alegando indeferir um requerimento de sesmaria, aprovado pela Câmara para a formação de uma fazenda de gado em Sorocaba, por estarem as terras já ocupadas por moradores que, embora não possuíssem os títulos legítimos, estavam estabelecidos com cultura no terreno em questão. Documentos Interessantes para a História e Costumes de São Paulo, v. 73, pp. 185-186. São Paulo: Gráfica João Bentivegna, 1952. Anos depois, a mesma postura foi adotada por Antonio Manoel de Melo Castro e Mendonça, quando este favoreceu os foreiros em litígio com o Convento do Carmo de Itu Documentos Interessantes, v. 87, p.188, São Paulo: Departamento do Arquivo do Estado, 1963; v. 29, p. 202 e v. 30, pp.221-222, ambos editados em São Paulo pela Typographia do Diário Official, 1899

2

Lucien Febvre. O problema da descrença no século XVI, pp. 15-16. Lisboa: Editorial Início, 1970.

Marc Bloch. Introdução à História, pp.125126. Lisboa: Publicações Europa-América, 1965.
As questões apresentadas neste informe fazem parte de uma pesquisa de mestrado em andamento que discute os conflitos gerados pela expansão da lavoura mercantil paulista entre fins do século XVIII e início do XIX, especialmente, entre os anos de 1782 e 1822. Inicialmente, a análise se baseava na legislação sesmarial promulgada no período, prevendo a análise das possíveis implicações destas leis sobre as formas de acesso à terra e à produção em São Paulo. Entretanto, notamos que, embora os assuntos relativos à propriedade ou posse de terras na Capitania de São Paulo fossem objeto de preocupação de seus governadores desde o Morgado de Mateus ${ }^{1}$, outras fontes, fundamentais para o estudo das mediações entre decisões político-jurídicas e condições sócio-econômicas da região, tais como memórias e relatórios elaborados por administradores da Capitania, indicavam que as formas de acesso a terra, bem como as leis a elas ligadas, não eram vistas como um problema quando se falava em aumento da produção agrícola.

Tendo em vista as questões levantadas pelos conjuntos documentais estudados, concentramos a análise nos discursos de contemporâneos acerca da Capitania de São Paulo. Redefinimos os objetivos da pesquisa buscando problematizar concepções, leis e práticas relativas ao mundo do trabalho em São Paulo no período, analisando como o processo de mercantilização da terra e da produção na América Portuguesa incidiu sobre a postura de grupos de poder locais interessados na ampliação dos contingentes de mão-de-obra, especialmente a indígena, ou na implementação de práticas comerciais, livres de amarras herdadas de instituições coloniais.

Os principais conjuntos documentais analisados foram a Collecçcão das Leis do Brasil (1808/1822), a Collecção das Decisões do Governo do Brasil (1808/1822), os Documentos Interessantes para a História e Costumes de São Paulo (nos quais constam os relatórios dos capitães generais e a documentação governamental paulista do periodo), a legislação extravagante portuguesa constante da Coleção Alberto Penteado de Leis, Decretos e Alvarás da Biblioteca do Museu Paulista/USP e um conjunto de memórias escritas por funcionários luso-brasileiros envolvidos na governança local. Estas memórias são a Dissertação sobre a Capitania de São Paulo, sua decadência e modo de restabelecê-la (1782), de Marcelino Pereira Cleto; as Reflexões sobre o estado em que se acha a agricultura na Capitania de São Paulo (1788) e a Memória sobre as Aldeias de Índios da Provincia de S. Paulo, segundo as observações feitas no ano de 1798, ambas de José Arouche de Toledo Rendon; os Jornais das viagens pela Capitania de São Paulo de Martim Francisco Ribeiro de Andrade, estipendiado como inspector das minas e matas, e naturalista da mesma capitania, em 1803 e 1804 e o Diário de uma viagem mineralógica pela Província de São Paulo no ano de 1805, também de Martim Francisco; a Memória sobre o melhoramento da Província de São Paulo (1810) e a Memória sobre a Agricultura no Brasil (1814), ambas de Antonio Rodrigues Veloso de Oliveira.

Para dar conta da análise destes grupos documentais, consideramos a especificidade de cada tipo de fonte reconhecendo que registros e testemunhos foram produzidos historicamente e expressavam as formas de pensar e os interesses dos homens que os formularam, pois "não há pensamento (...) que não tenha na sua própria substância a atmosfera de uma época (...). E nas quais ela imprime a marca de um estilo que ninguém ainda viu - que não se tornará a ver."2 A partir desta perspectiva pudemos inquirir e problematizar nossas fontes, analisando-as sem a ingenuidade de tomá-las como relato idôneo, pois "uma palavra, em suma, domina e ilumina os nossos estudos: 'compreender'. (...) Compreender, todavia, nada tem de passivo."3

Assim, partimos da constatação de que tanto os memorialistas supracitados quanto os capitães generais, em seus relatórios e ofícios, afirmavam a grande fertilidade das terras paulistas e a excepcional capacidade produtiva da região. Entretanto, na visão destes homens, tais recursos naturais estariam 
4

Ver a este respeito os relatórios dos Capitães Generais Bernardo José de Lorena (17881797) e de Antonio Manuel de Mello Castro e Mendonça (1797-1802), constantes da coleção dos Documentos interessantes, v.45, São Paulo: Duprat, 1924 e v.44, São Paulo: Typ. Cardozo Filho, 1913; respectivamente.

5

Ver a obra de Francisco Falcon, em especial cap. VI. A época pombalina. Política econômica e monarquia ilustrada. São Paulo: Ática 1993, e o artigo de Maria Odila da Silva Dias. "Aspectos da Ilustração no Brasil." Revista do Instituto Histórico e Geográfico Brasileiro. 278: 105-170, jan./mar. 1968.

6

Segundo indicações do Secretário de Governo de São Paulo, Manuel da Cunha de Azeredo Coutinho Sousa Chichorro, o cargo de Juiz da Alfândega de Santos esteve anexo ao de Juiz de Fora da mesma vila até 1802. Ver a "Memória em que se mostra o estado econômico e político da Capitania Geral de São Paulo". Revista Trimestral do Instituto Histórico, Geográphico e Ethnographico do Brasi., Tomo XXXVI, 1 a parte, Rio de Janeiro: B. L. Garnier, 1873, pp. 197-267.

7

Marcelino Pereira Cleto, "Dissertação a respeito da Capitania de São Paulo, sua decadência e modo de restabelecê-la. Em 25 de outubro de 1782." In: Roteiro e notícias de São Paulo Colonial (1751-1804). São Paulo: Governo do Estado, 1977, pp. 41-42. sendo desperdiçados devido à falta de atenção dada pelos governantes a São Paulo e à "preguiça" de sua população, tida como "vadia" e "indolente".

Na política de fomento metropolitana, implantada em São Paulo desde, pelo menos, o governo do Morgado de Mateus (1765-1775), a povoação da América Portuguesa estava intimamente ligada ao aumento de sua produção comercializável. Os memorialistas apontaram a necessidade de reformar a agricultura paulista mediante o aumento e a melhoria das técnicas produtivas, mas também por meio da incorporação de mais mão-de-obra a uma nova rotina de trabalho voltada à produção para o mercado. A temática da "decadência" é a tônica desses discursos, nos quais a "indolência" e a "preguiça" da população não escrava, o atraso das técnicas produtivas herdadas dos indígenas e a necessidade de povoar os sertões se tornam questões centrais. Temas que também figuram na documentação oficial estudada. Mas, nesse caso, ao lado do diagnóstico da "pobreza" da capitania e de seu povo, são propostos os "remédios" necessários e os avanços alcançados na solução de cada problema. Vale lembrar que, muitas vezes, tais "avanços" dependem exclusivamente da visão do capitão general que os relata, cioso de sua imagem junto à Coroa 4 .

Tanto os memorialistas quanto os governadores enviados à Capitania de São Paulo eram homens letrados, arregimentados pelo Estado Português a fim de expandir seus meios de controle e intervenção em suas possessões coloniais. Estiveram engajados na administração colonial em meio ao movimento de formação de burocratas e oficiais ilustrados, fomentado desde o consulado pombalino e reformulado e fortalecido durante os governos posteriores. ${ }^{5}$

Quando Marcelino Pereira Cleto escreveu sua Dissertação sobre a capitania de São Paulo em 1782, ocupava o cargo de Juiz da Alfândega de Santos ${ }^{6}$. Funcionário de carreira, provavelmente português, Cleto também foi ouvidor e corregedor da comarca do Rio de Janeiro, escrivão da devassa da Inconfidência Mineira e membro da Relação da Bahia. Esse autor afirma que São Paulo havia entrado em decadência desde o desmembramento das regiões de Goiás e do Cuiabá conquistadas pelos "paulistas", passando pela perda de sua autonomia administrativa (1748-1765) e pelo governo do primeiro capitão general, o Morgado de Mateus (1765-1775). Estes acontecimentos teriam concorrido para o desvio do comércio e do negócio das Minas Gerais, que passavam por São Paulo e pelo porto de Santos, em função da abertura dos novos caminhos.

Cleto critica a política metropolitana que determinou a concentração de poderes nas mãos do novo capitão general, apontando outras medidas que favoreceriam o aumento da produção e do comércio da região: especialmente o estabelecimento do comércio direto entre Santos e Lisboa, sem a "intromissão" de mercadores cariocas; o apoio aos mercadores por meio da melhoria dos caminhos e da instituição de imposições mais justas; bem como um controle mais efetivo do comércio dos gêneros de produção da América, exportados pelos demais portos da capitania, a fim de coibir que comerciantes paulistas, baianos e pernambucanos negociassem livremente, obrigando-os a pagar os devidos direitos à Real Fazenda. Os "remédios" para o restabelecimento da Capitania de São Paulo dar-se-ião "... em se pondo, primeiro que tudo o Governo, Junta da Fazenda, Ouvidoria e a Tropa na Vila de Santos, em se fazendo vir a ela anualmente dois ou três navios da Europa, em se facilitando o caminho de Santos para a Cidade de São Paulo e recomendando aos Generais e Ministros que castiguem exemplarmente os Vadios (...) tudo o mais naturalmente se há de ir seguindo e encaminhando (...)."7

José Arouche de Toledo Rendon escreveu durante o segundo semestre de 1788, provavelmente em virtude da nomeação do novo governador Bernardo José de Lorena, assinalando outras causas para o estado de "decadência" de São Paulo. Além de funcionário do governo, Rendon era um importante produtor paulista. Formado em Leis por Coimbra, em 1779, exerceu a advo- 
Os juizes das medições averiguavam se as terras pedidas em sesmarias eram realmente devolutas e procediam à correta demarcação das mesmas; quando ocupou este cargo Rendon provavelmente lidou com os problemas relativos à ocupação das terras paulistas por posseiros e rendeiros ou pequenos produtores não engajados nos projetos de lavoura comercial que se queria implantar.

9

Rendon também arrematou o contrato das passagens dos Cubatões Gerais de Santos e Mogi das Cruzes (1796-1798), foi diretor gera dos índios (1798), fiscal da Casa de Fundição do Ouro de São Paulo (1799), Juiz de Órfãos (1806-1808), Procurador da Fazenda junto à Fábrica de Ferro de Ipanema (1811), Presidente do Conselho de Guerra da Província (1821), deputado à Assembléia Constituinte dissolvida em 1823, membro do Conselho Provincial de São Paulo e Diretor do Curso Jurídico de São Paulo (1828-1833). Ver a este respeito a introdução às suas Obras, escrita por Paulo Pereira dos Reis.

\section{0}

José Arouche de Toledo Rendon, "Reflexões sobre o estado em que se acha a agricultura na Capitania de S. Paulo". In: Rendon, Obras, São Paulo: Governo do Estado, 1978, p.3.

\section{1}

Ver Pasquale Petrone. Aldeamentos paulistas. São Paulo: Edusp, 1995, especialmente o capítulo 2 e John Monteiro. Negros da Terra. São Paulo: Companhia das Letras, 1994, capítulos 1 e 2 .

12

Idem, ibidem.

\section{3}

Kenneth Maxwell. A devassa da devassa. Rio de Janeiro: Paz e Terra, 1995, p.31.

\section{4}

Coleção Alberto Penteado de Leis, Decretos e Alvarás. Acervo de Obras Raras da Biblioteca do Museu Paulista/USP, OR. 801, fl. 122 e fl. 342

\section{5}

Idem, fl. 366 a fl. 387.

16

José Arouche de Toledo Rendon, op. cit., p.3. cacia em São Paulo e foi juiz de medições de sesmarias entre 1782 e $1783 .{ }^{8}$ Posteriormente, ocupou diversos cargos em órgãos administrativos e judiciais ${ }^{9}$, enquanto seguia como negociante e produtor, tendo chegado ao posto de Tenente General das Milícias.

Em suas Reflexões sobre o estado em que se acha a agricultura na Capitania de São Paulo, Rendon ressalta a necessidade de fazer o litoral e o sertão produzirem mais a partir da reorganização da mão-de-obra local e de medidas governamentais que racionalizassem a estrutura produtiva paulista. 0 autor situa a decadência de São Paulo exatamente em 1755, quando da decretação da liberdade indígena pelo governo metropolitano, pois: "... de todos os mais vadios eram os índios. Na verdade antes que o Senhor Rei D. José, de saudosa memória, os declarasse livres, não eram supérfluos ao Estado; os paulistas, que os conquistaram, os faziam trabalhar; porém desde a época da soltura da sua natural liberdade, que no ano de 1755, lei de 6 de junho, tornaram ao costume de não plantarem para a sua sustentação."10

Desde o início da ocupação do território que depois viria a formar a Capitania de São Paulo, o braço indígena foi usado como principal força de trabalho. ${ }^{11}$ Medidas relacionadas à liberdade do indígena convertido foram tomadas desde o século XVI ${ }^{12}$, entretanto, maiores obstáculos à sua efetiva escravização só vieram à luz no século XVIII, quando o Marquês de Pombal passou a encarar o indío como o principal meio para colonizar e defender 0 "Estado do Brasil"13. Em 6 de junho de 1755 uma lei declarou a liberdade das "pessoas e do comércio dos índios"14. Pouco depois, em 1758, foi promulgado o "Diretório dos Índios", que mandou instituir um diretor para cada povoação indigena, encarregado de estimular sua produção e comércio. ${ }^{15} \mathrm{~A}$ partir da promulgação destas leis, todo o governo secular dos índios ficou a cargo exclusivamente de autoridades nomeadas pelo governo metropolitano. É provável que Rendon, membro de uma tradicional familia paulista, visse na legislação que "libertou" os indigenas e instituiu os diretores um entrave ao bom andamento das lavouras e dos negócios de produtores paulistas, pois, para ele, uma das maneiras de fazer a capitania voltar a crescer seria recriar meios que fizessem a gente indigena voltar ao "trabalho".

Assim, ressaltando sempre a "vadiagem" da população, o autor traçou em suas Reflexões... um quadro bastante sombrio de São Paulo na época, marcado pela pobreza gerada pela falta de povoação e pela falta de apego da população livre ao trabalho. Dessa forma, a principal tarefa das autoridades metropolitanas seria educar a população para o trabalho, visto que São Paulo seria muito rica se a população livre que trabalhava a terra somente nos três ou quatro meses em que retirava da lavoura os gêneros necessários a sua subsistência, passasse a se dedicar integralmente à lavoura.

Para Rendon, a maior dificuldade estaria em fazer com que a "gente livre não aldeada" trabalhasse; pois esta "gente"- provavelmente forros, brancos pobres e mestiços - só se dedicaria ao trabalho no campo se fosse coagida a escolher entre a agricultura e o serviço nos "regimentos das cidades". Daí a necessidade de fazer com que os diretores das aldeias obrigassem os indios a cultivarem suas terras, pois "... assim seriam úteis ao Estado e a si mesmos e evitariam-se muitos latrocínios."16

Anos depois, Martim Francisco Ribeiro de Andrada também determinou os problemas que estariam causando o "atraso" da Capitania de São Paulo. Os Jornais... e o Diário de uma viagem mineralógica pela Província de São Paulo foram escritos enquanto o autor ocupava os cargos de Diretor das Minas e Matas da Capitania de São Paulo e Inspetor da Fábrica de Ferro de São João do Ipanema (em Sorocaba), nos quais permaneceu por vinte anos. Tal como os outros bacharéis, seus contemporâneos formados em grandes universidades européias, especialmente Coimbra, Martim Francisco procurou aplicar conhecimentos eruditos e científicos na análise do meio americano. Dessa forma, seus estudos não se limitam a descrever os aspectos naturais das regiões visi- 
17

Martim Francisco Ribeiro de Andrade. "Jornais das viagens pela Capitania de São Paulo". In: Roteiro e notícias de São Paulo Colonial (1751-1804). São Paulo: Governo do Estado, 1977, p. 146

18

Idem, p.148. Grifos nossos.

19

Idem, p. 166.

20

Ver a este respeito Documentos Interessantes, especialmente os volumes citados na nota $1 \mathrm{e}$ o vol. 95, pp. 348-349, São Paulo: Editora da UNESP/Edições do Arquivo do Estado, 1990, no qual constam documentos relativos a venda e "rateio" de sesmarias a posseiros que já ocupavam os terrenos doados.

21

Martim Francisco Ribeiro de Andrade, op. cit., p.167.

22

Medida que será implantada por decreto do Príncipe D. João em novembro de 1808.

23

Martim Francisco Ribeiro de Andrade, op. cit., p.167. tadas. Entre descrições geológicas e estudos mineralógicos do terreno, analisa as potencialidades agrícolas do solo e da população que o habita, inclusive quanto à aplicação destas gentes ao trabalho. Ao mesmo tempo, propõe meios para o melhor aproveitamento econômico da região, discutindo questões que envolviam a povoação e a civilização do indígena.

Os relatos de Martim Francisco se referem a três viagens: uma entre São Paulo e Itu; outra entre Sorocaba e Curitiba e a terceira pelo litoral paulista, entre Santos e Cananéia. Já em Barueri, Martim Francisco se impressionara com o bom estado da fazenda do vigário da Aldeia, onde apenas seis escravos cuidavam das plantações de fumo, milho, feijão, bananeiras e mandioca, além da criação de seiscentas cabeças de gado. A partir da observação dessa fazenda, o autor analisa as possibilidades de produção da terra paulista, afirmando: "Se toda esta capitania situada debaixo do melhor céu do mundo, e tão cheia de riquezas naturais, fosse habitada por homens industriosos, amigos do trabalho, em breve chegaria ao máximo da prosperidade; o povo seria feliz e abastado..."17 Repete-se, dessa forma, o mesmo discurso sobre a " decadência" e a falta de amor da população ao trabalho, comum aos memorialistas paulistas desde vinte anos antes de Martim Francisco ter escrito tais relatos.

Segundo o autor, as terras do termo de Paranaiba permaneceriam incultas, exceção feita a duas fazendas de algodão e outros gêneros. Entretanto, ainda sobre essa mesma vila, o mineralogista descreve a paisagem praticamente desmentindo o que dissera antes sobre a produção agrária paulista, pois confessa "... que o apinhoamento de fazendas, e abundância de terras cultivadas diminuiram em parte o desprazer, que me causou esta marca sem réplica da indolência paulista." 18 Se anteriormente o autor afirmara que, nessa mesma região, havia grandes porções de terras incultas e, depois, deleitou-se com a visão do "apinhoamento" de fazendas, o quê, para ele, significaria cultivar e trabalhar? Estaria se referindo a unidades produtivas tais como a do vigário de Barueri, organizadas segundo as novas diretrizes da produção para o mercado, diferentemente da lavoura de subsistência comum em São Paulo no periodo?

Esta possibilidade de análise ganha forças se considerarmos a imagem que o mineralogista constrói de Itu: uma das maiores vilas da capitania, próspera, bonita, dotada de boas igrejas e dedicada à cultura de café e à de cana de açúcar, voltada à exportação com o Reino. Em contraposição, a vizinha Sorocaba, é apresentada como o oposto da vila de Itu: desordenada, feia, mantendo como único comércio o das tropas vindas do Sul, populosa, mas repleta de habitantes "doentes" e "insensatos"; vale ressaltar que a produção desta vila consistia em milho, feijão, algodão e um pouco de café e açúcar. 19 Assim, Itu aparece em várias partes do relato como uma espécie de modelo a ser seguido: habitada por população laboriosa, produz alta receita para a Coroa e dedica-se à cultura de um gênero exportável. Por outro lado, também foi a região onde mais ocorreram litígios e "acordos" relacionados à posse e à propriedade de terras no período, conforme pudemos depreender da documentação governamental consultada. ${ }^{20}$

Martim Francisco fez ainda uma longa digressão acerca da necessidade de chamar os nativos à convivência com o branco, defendendo o estabelecimento de novas povoações nos lugares habitados pelas nações indígenas. ${ }^{21}$ Para isso, seria preciso aumentar o número de habitantes em São Paulo permitindo-se a ocupação da terra por estrangeiros22; promovendo-se casamentos, formando sociedades agronômicas e adiantando-se a agricultura: "... considerando a vida de lavrador, não a sobrecarregando de impostos, arrancando-a da escravidão de outras classes"23, numa provável referência ao endividamento dos lavradores junto aos negociantes. Tal como Marcelino Pereira Cleto e José Arouche Rendon, Martim Francisco liga povoação e agricultura, mas não um tipo de agricultura qualquer, e sim aquela melhor direcionada e regulada de acordo com as necessidades do comércio dos gêneros paulistas. 
24

Maria de Lourdes Viana Lyra. A utopia do poderoso império. Rio de Janeiro: Sette Letras, c. 1994, p.44.

25

Idem, p.45 e seguintes.

26

Segundo o recenseamento de 1767 , o pai de Veloso de Oliveira, comerciante, morador da Cidade de São Paulo, acumulava um montante de 28:000\$000. Ver a este respeito os Documentos interessantes, v. 62, São Paulo: Edição do Instituto Histórico e Geográfico de S. Paulo, 1937.

27

Antonio Rodrigues Veloso de Oliveira. Memória sobre o melhoramento da Província de São Paulo. São Paulo: Governo do Estado, 1978, p.30.

\section{8}

Idem, p. 56. 0 fim do regime de frotas entre a América Portuguesa e o Reino deu-se em 1765, mesmo ano em que a administração da Capitania foi restabelecida. Dois anos antes, o Conde de Bobadela, administrador do Rio de Janeiro na época em que São Paulo the foi subordinada como comarca e que era acusado de prejudicar e abandonar São Paulo, havia falecido. Em 1789, o então Capitão General Bernardo José de Lorena determinou que os gêneros a serem exportados pela capitania saissem, necessariamente, pelo porto de Santos, sete anos depois, Antonio Manoel de Melo Castro e Mendonça suspendeu tal decisão, que foi retomada por José da Franca e Horta até ser definitivamente abolida pela Coroa em 1807.
Nos relatos apresentados, Martim Francisco cumpriu seu papel de funcionário de um Estado absolutista atuante num domínio ultramarino, analisando a realidade que o cerca e propondo as reformas necessárias para integrar a Capitania na qual nasceu ao projeto de Império Português, até então defendido pelos ilustrados portugueses dos dois lados do Atlântico. A política de reformas iniciada no consulado pombalino - fundamentada na reorganização administrativa, na modernização da produção no Reino e nos Domínios e na reorganização das instituições científicas e de estudo, adaptada nos anos finais do século XVIII -, incidiu sobre as propostas que os memorialistas portugueses apresentaram, especialmente os ligados à Real Academia das Ciências de Lisboa, alicerçando o ideal de "união e reciprocidade" entre as diversas partes do Império Português. ${ }^{24} \mathrm{~A}$ idéia de colônia inteiramente subordinada à metrópole daria lugar à concepção de unidade imperial, daí a atuação de ilustrados portugueses nascidos na América no esforço de conhecer e explorar os recursos do império colonial português 25 .

Entretanto, após 1808, a reorganização do Estado Português em terras americanas tornou difícil a articulação de propostas em termos de interdependência das diversas partes do Império com um centro europeu agregador, representado pelo Reino de Portugal.

Foi em meio à implantação do Estado Português no Brasil que as duas memórias de Antonio Rodrigues Veloso de Oliveira foram compostas. 0 autor, nascido em São Paulo, filho do homem mais rico da cidade na época 26 , fez seus estudos em Coimbra, onde se formou em leis em 1777. Exerceu vários cargos de magistratura nas Ilhas da Madeira e no Reino, retornou ao Brasil depois da invasão francesa, sendo nomeado chanceler quando da criação da Relação do Maranhão em 1811. Foi neste intervalo que escreveu a Memória sobre o melhoramento da Província de São Paulo, endereçada a D. João em 1810, mas publicada somente em 1822. Depois disso, ocupou diversos cargos administrativos e de justiça na América Portuguesa, tendo escrito a Memória sobre a Agricultura no Brasil, em 1814.

Para Veloso de Oliveira, o aumento populacional e produtivo só poderia ocorrer se o governo atuasse na instrução dos lavradores e na introdução de técnicas mais modernas de cultivo e beneficiamento dos gêneros. Além disso, seria necessário mostrar ao povo paulista, que tinha "horror ao trabalho", os benefícios e o "lucro fácil", que adviriam da produção para comércio, incentivando-o com empréstimos para que, enfim, pudesse se formar enquanto "povo social", "enérgico, rico, vigoroso, sábio e respeitável".27 Ainda em Veloso de Oliveira encontramos a visão de um povo indolente e pobre, mas aqui, não são apenas as poucas virtudes desse povo que causam a inação da produção, e sim a ausência de estímulos e a pouca instrução dedicadas aos lavradores.

Para este autor, as principais razões que estariam retardando a agricultura em São Paulo eram: a incúria dos governadores encarregados da administração da capitania, inclusive quando esteve subordinada ao Rio de Janeiro; o antigo regime de frotas que teria prejudicado o livre comércio; a perda do comércio com a região das Minas Gerais e de Goiás; a constante perda de povoação da capitania, causada pelo envio de tropas paulistas às guerras no Sul; e as decisões dos capitães generais que limitaram o comércio aos negociantes estabelecidos em Santos. ${ }^{28}$

Para Veloso também estava em pauta o modo como a política de fomento da Coroa vinha sendo aplicada depois da transferência da Corte, principalmente no que se refere à necessidade de modernizar os sistemas tributários e liberalizar as vias de comércio interno e externo. Por isso, o autor defendia a constituição de leis comerciais, baseadas na liberdade e na segurança, e a abolição dos inúmeros direitos de passagem, que oneravam os gêneros comercializados, em troca da instituição de um direito único de saída.

No capítulo mais longo de sua Memória Veloso de Oliveira fez várias propostas para aumentar a povoação de São Paulo. 0 maior problema para o 
Antonio Rodrigues Veloso de Oliveira, op. cit. pp. 75-76.

30

Ver Documentos interessantes, v.58. São Paulo: Edição do Instituto Histórico e Geográfico de S. Paulo, 1937, p.69-70, p.8384, p.101-102, p.286-288.

31

Collecção das Leis do Brasil, 1809. Rio de Janeiro: Imprensa Nacional, 1891, p36.

32

Idem, 1808, Carta Régia de 13 de maio e Carta Régia de 24 de agosto, sobre a "guerra ofensiva" contra os Botocudos habitantes das margens do Rio Doce; Carta Régia de 5 de novembro, ordenando o início da guerra contra os "bárbaros indios" que "infestavam" os campos de Curitiba e Guarapuava.

33

Antonio Rodrigues Veloso de Oliveira. "Memória sobre a agricultura no Brasil". Revista Trimestral do Instituto Histórico, Geográphico e Ethnographico do Brasil, Tomo XXXVI, 1a parte, Rio de Janeiro: B. L. Garnier, 1873, pp. 91-133. aumento da população, e conseqüentemente da produção, era o modo como os pobres faziam a terra produzir: pouco e sem método, sem geração de riquezas para o Estado. Além de novas povoações formadas pela imigração, seria necessário tornar os índios mais "úteis", tirando-os dos "bosques onde vivem desgraçadamente" através da indústria e do trabalho. ${ }^{29}$

Na mesma época em que tais propostas foram formuladas, novas levas de "indios bravos" passaram a ser incorporadas numa espécie de "política de civilização", igualmente defendida por Veloso de Oliveira, conforme pudemos constatar. Em 1809, vários ofícios foram expedidos pelo governo paulista permitindo a organização de "entradas" contra os "bugres" acusados de atacar as vilas de Itapetininga, Paranapanema, Itapeva, Porto Feliz e Vila Nova do Príncipe. 30 Os indios, assim aprisionados, poderiam permanecer em cativeiro por quinze anos, nos termos da Carta Régia de $1^{\circ}$ de abril de 1809 que aprovou o "Plano para o Povoamento e Civilização dos índios dos Campos de Guarapuava", voltado ao mesmo tempo para a "civilização" indígena e para a povoação daqueles sertões, através da introdução de colonos brancos pobres. ${ }^{31}$ Desta lei e de outras promulgadas no mesmo período podemos concluir que, também, para a Coroa a "civilização" dos indígenas era fundamental - ponto em que os memorialistas e o governo concordavam plenamente. 32

Na sua obra de 1814, a Memória sobre a agricultura no Brasil, Veloso de Oliveira retoma teses já defendidas na memória de 1810, trabalhando-as mais detalhadamente, em especial, a questão da povoação e da forma de ocupação das terras pelos lavradores. Interessante notar como, neste outro escrito, o autor passa a criticar a inexistência, no Brasil, de um corpo de leis próprias e sólidas, capazes de "instruir os povos", formando seus costumes e sendo mantidas por eles. Estas leis deveriam criar e sustentar os três principais agentes da fortuna pública: a agricultura, o comércio e a manufatura. ${ }^{33} \mathrm{As}$ duas memórias de Veloso de Oliveira convergem, contudo, em suas propostas centrais: a necessidade de povoar o Estado do Brasil, de mudar as diretrizes da ocupação da terra efetivamente em prática (e não a legislação a respeito) e de racionalizar a produção e o comércio de gêneros agrícolas e manufaturados, principalmente, no que se refere à cobrança de impostos. Um dos traços de sua obra é a preocupação em instalar no Estado do Brasil normas e instituições, capazes de atender à nova situação que a instalação da Coroa na América Portuguesa vinha gerando. 0 autor propõe alterações fundamentais nas formas de trabalho existentes, desse modo, se era preciso criar um "colonato" disciplinado, seguindo novas diretrizes de produção, também era necessário mostrar as falhas do processo administrativo colonial que, até aquele momento, dificultara a implantação de novas políticas de povoamento e de produção para mercado. Indicando, assim, medidas necessárias ao enraizamento do Império Português na América.

Embora carreguem as especificidades de seu tempo e dos autores que as produziram, as fontes ora apresentadas apontaram as principais questões a serem trabalhadas na pesquisa. Entre a confecção do primeiro e do último texto das memórias citadas decorreram 32 anos, entretanto, cada autor expôs suas análises e propostas para a melhoria da produção e do comércio como se nada tivesse ocorrido de significativo na Capitania de São Paulo, economicamente falando, durante todo esse período.

Os dois memorialistas do setecentos escreveram num momento em que já se faziam sentir os resultados da política metropolitana de incentivo à produção na América Portuguesa desde a ascensão de Pombal e, em São Paulo, desde o governo do Morgado de Mateus. Ambos enfatizam a necessidade de criação de mecanismos para o aumento da população dedicada à agricultura voltada ao comércio, principalmente dos gêneros mais facilmente exportáveis, via porto de Santos, para Lisboa. Segundo o que se depreende dessas duas memórias, eram necessárias não só modificações no sistema de 
34

Os mapas econômicos e políticos da Capitania de São Paulo podem ser consultados na coleção do Documentos Interessantes para a história e costumes de São Paulo e nas Memórias do Capitão General Antonio Manuel de Melo Castro e Mendonça: Memória econômico política da Capitania de São Paulo e Memória sobre os objetos mais interessantes da Capitania de São Paulo entregue ao $1 / \mathrm{m}^{\circ}$ e Exm. ${ }^{\circ}$ Sr. Antonio José da Franca e Horta..., datadas de 1800 e 1802 respectivamente, também em Documentos Interessantes, v.44. Sobre a população paulista do periodo, consultar a obra de Maria Luísa Marcílio. Crescimento demográfico e evolução agrária paulista. 1700-1836. São Paulo: Hucitec/ Edusp, 2000. A respeito das vias de comércio interno na América Portuguesa consultar a obra de João Fragoso. Homens de grossa aventura. Rio de Janeiro: Arquivo Nacional, 1992.

35

Ver a este respeito os capítulos II e III do Livro Terceiro de Spix e Martius. Viagem pelo do Brasil, 1817-1820. 2a ed., São Paulo: Melhoramentos, 1968 e o relato de SaintHilaire a respeito dos benefícios da cultura da cana para as vilas de Itu, Campinas e São Carlos, citado em diversos trechos de sua primeira Viagem à Província de São Paulo. Belo Horizonte: Itatiaia/São Paulo: Edusp, 1976. contratação das passagens e impostos ou melhorias dos caminhos, como também alterações essenciais no modo como a política metropolitana de incentivo à produção vinha sendo aplicada na Capitania de São Paulo.

Para Pereira Cleto, e provavelmente para grupos santistas a ele ligados, o maior problema estaria na "pouca atenção" dispensada à marinha paulista, inclusive no que diz respeito ao retorno de órgãos tão importantes quanto a Provedoria da Fazenda e a Ouvidoria, ao planalto. Já para Rendon, havia uma situação de pujança, anterior à restauração de São Paulo como capitania autônoma, que foi suprimida quando se retirou das mãos dos produtores paulistas a possibilidade de manejar a mão-de-obra indigena disponivel, o que poderia ter significado o empobrecimento de segmentos proprietários, faltos de recursos para adquirir escravos africanos, ou mesmo, ter impedido o fortalecimento desses setores no momento em que a memória foi escrita, visto os dados que apontam para a expansão econômica na região no periodo. Por outro lado, para favorecer o ingresso de mão-de-obra "livre não aldeada" na lavoura comercial se fazia necessário depreciar o trabalho de base familiar - executado em pequenas possessões de terra voltadas à produção de subsistência -, em termos de "vil pobreza", "vadiagem" e "indolência".

Em seus Jornais..., Martim Francisco expôs não só observações relativas ao melhor aproveitamento do solo e das matas paulistas, mas também planos de desenvolvimento que implicariam a reorganização da produção e das relações de trabalho da população "vadia", de modo a que se atendesse à política da "reciprocidade" colonial, na qual metrópole e ultramar formariam um todo unido por meio de interesses mútuos representados pelas trocas comerciais.

No início do século XIX, o Governador e Capitão General Antonio Manoel de Melo Castro e Mendonça apresentou relatórios favoráveis sobre a produção de gêneros em São Paulo, já que sua população vinha apresentando altas taxas de crescimento, desde meados do século anterior, e a capitania estava plenamente integrada ao comércio interno de gêneros de subsistência. ${ }^{34}$ Também viajantes que atravessaram São Paulo poucos anos depois notaram a abundância de roças de milho, mandioca, fumo e feijão, além da criação de gado e da lavoura da cana, tanto no Vale do Paraíba, quanto na região de Itu. 35 Se havia produção suficiente para a "exportação" de gêneros para outras regiões da América Portuguesa, por que a persistência, até em um estudo sobre mineralogia, do discurso da pobreza e da indolência dos povos paulistas? Seria a inadaptação dessa população aos novos projetos ilustrados, de aumento da produção voltada à exportação e de maior controle sobre os livres pobres, que vinham sendo implantados desde fins do periodo pombalino?

Veloso de Oliveira ressaltou, em sua obra, a necessidade de se elaborar uma política governamental condizente com o novo estatuto do "Estado do Brasil", na condição de sede da Monarquia Portuguesa. Daí, suas propostas de incentivo a um novo tipo de povoação e de ocupação de terras por mão-deobra indigena ou por imigrantes, que estariam totalmente dependentes do Estado ou dos proprietários que os instalassem, instruissem e "ajudassem" a produzir. Assim, perpassa, por todo o texto, o caráter mercantil da utilização dessa mão-de-obra, bem como a necessidade de se transformar a terra em mercadoria. A análise em separado das duas Memórias desse autor leva a crer que suas expectativas frente às reformas institucionais, por ele preconizadas, para a América Portuguesa não foram implementadas, pois em seu escrito de 1814, por mais de uma vez, lamenta as "extorsões e violências" praticadas pelos contratadores das passagens e impostos, a "arbitrariedade" dos governadores e o "sistema colonial", que ainda determinariam os rumos da política.

A partir das questões apontadas neste informe, foram definidos três principais problemas a serem desenvolvidos na dissertação. 0 primeiro diz respeito ao próprio termo "decadência", entendido não como uma situação de fato, mas como um elemento do discurso de homens ligados a governança 
local, usado para justificar interesses dos grupos que se viram prejudicados pela concentração de poder nas mãos do capitão general, pelas imposições que oneravam o comércio ou pela dificuldade em controlar a mão-de-obra indígena. Em segundo lugar, fez-se necessário analisar as razões pelas quais a "civilização" indígena através do trabalho em lavouras comerciais era tão importante, tanto no discurso memorialista quanto no governamental, visto a constância com que este tema é tratado nas fontes estudadas. Por fim, se os discursos acerca de São Paulo apontavam que a capitania precisava se "recuperar" ampliando sua atuação nas linhas de comércio atlântico, a despeito de sua participação nas redes de comércio interno, é preciso problematizar a forma como diferentes grupos encaravam a inserção paulista no Império Português e como a transferência da Corte em 1808 modificaria suas propostas. 